\title{
Assessment of voluntary counseling and testing service utilization and associated factors among Debre Markos University Students, North West Ethiopia: a cross-sectional survey in 2011
}

Girmay Tsegay ${ }^{1 *}$, Melkie Edris ${ }^{2}$ and Solomon Meseret $^{2}$

\begin{abstract}
Background: Voluntary Counseling and Testing (VCT) is the key entry point to prevention, care, treatment and support services, where people learn whether they are infected or not and to understand the implications of their HIV status and make informed choices for the future.

Methods: A cross sectional study design was done among 753 students drawn from selected departments in Debre Markos University, Ethiopia, using multi-stage sampling technique. Self-administered questionnaire was used to estimate the prevalence of VCT service utilization and to assess associated factors. Data were entered and analyzed using SPSS version 16.

Results: 711 students were participated in the study, of whom, 521 were males. Majority (93.8\%) were within the age range of 15 to 24 years. The mean age was 21.5 (3.2 $)$; most of the respondents (91.6\%) were single. Majority (81.4\%) heard about the confidential VCT service, and their major sources of information were mass media (73.3\%) and health workers (71.1\%). The study revealed that $58.5 \%$ of the study participants had undergone voluntary counseling and testing. It was shown that VCT service utilization was significantly associated with availability of ART drug in VCT site, heard presence of confidentiality, perceived stigma, risk perception and knowledge about HIV.

Conclusion: The major factors identified for increased VCT service utilization were knowledge about availability of ART drug in VCT site, information about confidentiality, absence of perceived stigma, higher risk perception and knowledge about HIV. Therefore, actions targeting on these predictors are necessary to effectively enhance the use of the VCT services utilization.
\end{abstract}

Keywords: University students, VCT, Utilization, Associated factors

\section{Background}

HIV/AIDS remains a major public health problem all over the world. UNAIDS (2008), estimate that 33 million people are living with HIV/AIDS globally. Sub-Sahara accounts for two-thirds of the global HIV/AIDS burden; Ethiopia is one of the Sub-Saharan countries highly affected by HIV/AIDS pandemic. According to the 2007 Ethiopian Ministry of Health report, the adult prevalence of HIV infection in Ethiopia was estimated at 2.1\% [1-4].

\footnotetext{
* Correspondence: girmshe@gmail.com

${ }^{1}$ School of public Health, College of Medicine and Health Sciences, Debre Markos University, Debre Markos, Ethiopia

Full list of author information is available at the end of the article
}

Youth (15-24 years) are vulnerable to HIV because of the strong influence of peer pressure and the development of their sexual and social identities which often lead to experimentation [5]. The majority of young people in the age group (15-24 years) are at risk of HIV infection due to their engagement in unsafe sex, injection drug use, exposure to contaminated blood and blood products or unsterilized skin-piercing procedures [6]. The young age group is the most productive segments of the population that form the basic education sector which is vital to the creation of human capital this will affect both the demand and supply of education $[7,8]$. 
It has been estimated that most of the 37 million people worldwide living with HIV do not know that they are carrying the virus and the proportion is higher in countries worthily affected by the epidemic [9]. The first pillar of HIV prevention is voluntary counseling and testing (VCT). Despite the high number of people already living with HIV/AIDS, it is estimated that less than $10 \%$ are aware they are infected, mainly because of the limited availability, access, and use of VCT [10]. This fact greatly hinders efforts to respond to the AIDS epidemic, as people have to know if they are infected in order to access services [10].

Voluntary counseling and testing is also an effective strategy for facilitating behavior change for both clients, whose test result is either negative or positive [11]. Different studies have shown the effects of VCT including a decrease in unprotected sexual intercourse, a reduction in multiple partners, an increase in condom use, and more clients choosing abstinence. In addition, VCT is an important entry point to other HIV/AIDS prevention services, including prevention of mother to child transmission (PMTCT), prevention and management of HIV related illnesses, and social support (11).

Despite the high levels benefits of voluntary counseling and testing service, VCT utilization was low, particularly among young and active segment of populations. Research done in Uganda, Zambia, and among health care professional students of Kilimanjaro region revealed that voluntary counseling and testing service utilization were $10 \%, 14 \%$ and $34.5 \%$ respectively [12-14].

Various research findings in Ethiopia revealed that utilization of voluntary counseling and testing service is low and its level of utilization varies among different segments of the population [15-17]. Researches, conducted among university students corroborate this fact. For instance, a study done among Bahir Dar University students showed the utilization of VCT was 38.6\%. Similarly, among Debre Birhan Teachers Training College students $35.19 \%$ of the respondents have ever been tested for HIV despite higher level of knowledge and favorable attitude towards VCT among the study population [15-17].

The aim of this study was to assess VCT service utilization and associated factors among Debre Markos University students, North West Ethiopia in 2011. The findings of the study will be helpful to expand and improve the service of VCT, contributing to the HIV/AIDS prevention and control programs in the University.

\section{Methods}

This study was carried out in March 2011 among Debre Markos University students, Debre Markos Town, Ethiopia. Debre Markos is the capital city of East Gojjam Zone and is located in the North West part of the country bounded by Gozamen Woreda (district) in the North,
South, and East, and Aneded Woreda (district) in the West. It covers an area of 6 million square meters and located on the main road of Addis Ababa (national capital)-Bahir Dar (regional capital), $300 \mathrm{~km}$ away from Addis and $265 \mathrm{~km}$ from Bahir Dar. It was estimated that the total population living was 70,857 people in 2008 , of which about 21,257 were youth group. Two NGO clinics/ FGAE and Marie Stops International providing reproductive health services to the target adolescent and youth groups; three government health center and one referral hospital provide VCT service. The only VCT centre in Debre Markos University campus is the one run by an NGO, African Initiative. Debre Markos University is one of the new universities in the country that were established in 2005. At the present time the university has seven faculties, Agriculture \& Natural Resource, Business \& Economics, Health Science, Law, Natural \& Computational Sc., Social Sc. \& Humanities, and Technology. The total number of regular students in all batches was 5746, out of which 1618 were female students.

This study utilized an institution-based cross-sectional study design with quantitative data collection method. The study population included all undergraduate students (Year I to year III) attending professional training at Debre Markos University. Those aged below 18 years and others who didn't want to participate in the study and students who were seriously ill were excluded from the study.

The sample size was determined by Epi Info 2002 software package using a single proportion formula for cross-sectional survey, based on the prevalence of VCT service utilization (38.6\%) during the past year among Bahir Dar University students [17]. Using 5\% margin of error at 95\% confidence level, the sample size required was 753 after considering 10\% non-response rate. Multistage sampling technique was used to select study subjects. Firstly, students in the University were stratified by their field of study as health science and non health science. Secondly, one department from health science and five departments from non health science were selected using simple random sampling based on proportion. Thirdly, students in each field of study were further stratified by their year of study assuming that their field of study and duration of stay in the campus affect their VCT utilization. Finally, students were selected from each batch proportionally by simple random sampling technique using computer generated random numbers.

Data collection was done by pre-tested, pre-coded, and self- administered questionnaire with open and closed ended questions. This structured questionnaire adapted from similar previous studies and sample of questionnaire that was modified to the study setting. The questionnaires were self-administered to collect socio-demographic information and other important variables that include: VCT 
utilization, individual's knowledge, sources of information and other variables. Pretesting of the questionnaire was performed on few students of Bahir Dar University students to verify clarity of the instrument used.

The questionnaire is originally prepared in English language and then translated to Amharic and again retranslated to English by language experts for consistency. Data collectors were nurses that were recruited and trained for one day by the principal investigator. Each questionnaire filled was checked for completeness of the information jointly by the facilitators. To reduce the error arising from respondents, $5 \%$ of randomly selected questionnaire was rechecked for consistencies by the principal investigator.

The collected data were cleaned, coded, entered into SPSS and analyzed using SPSS computer soft-ware package version 16. Summary statistic of socio-demographic variables was resented using frequency tables and graphs. Bivariate analysis was done and variables with $\mathrm{p}$ value less than 0.2 were included in the multiple logistic regression analysis which was performed to assess the association between VCT utilization and various explanatory variables. P-value less than or equal to 0.05 was taken as cut of value to be significant. Odds ratio and $95 \%$ confidence interval was also constructed along with the corresponding $\mathrm{p}$ value.

The ethical review committee of the School of Public Health in Gonder University, College of Medicine and Health Sciences, approved the study for its ethical and scientific merit.

Communication was held with Debre Markos University and the University supported the undertakings of this study in writing to all the respective sampled departments. Informed verbal consent was also obtained from the respective students for their participation after the nature of the study was fully explained in their local languages. The right to withdraw from the study at any time was also communicated and respected. At the end of the interview all students were advised and encouraged to follow their peer groups to utilize the VCT service.

\section{Results}

From the total of 753 students, 711 completed the questionnaire adequately making the response rate $94.4 \%$. The mean age of the students was 21.5 with standard deviation of 3.2. The number of students from rural areas encompasses 406 (57.1\%). About 521 (73.3\%) and $651(91.6 \%)$ of students were males and single respectively. Around 667 (93.8\%) of students were found at the age group of 15-24, and 636 (89.5\%) were Orthodox Christian religion followers. Five hundred ninety five (83.7\%) students belong to Amhara ethnic group and $588(82.7 \%)$ were non-health science students (Table 1).
About 579 (81.4\%) of students have heard the presence of confidential VCT service and $668(73.3 \%)$ of them were heard from mass media as a primary source of information. The major reason for utilization of voluntary counseling and testing by students were to know their status 341 (82\%) followed by for marriage 29 (7\%). Six hundred eleven (85.9\%) of students know the availability of ART drug in the voluntary counseling and testing sites. Around $561(78.9 \%)$ students prefer face to face way to get HIV/AIDS test result and about $682(96 \%)$ students were knowledgeable about HIV/AIDS (Table 2).

Study participants were compared for reported reasons of not utilizing voluntary counseling and testing (VCT) service for HIV/AIDS, about 67 (22.7\%) were reported unwilling to utilize VCT service due to didn't feel at risk, 54 (18.3) have no reason for not utilizing VCT, 39 (13.2\%) of the students were trusting themselves and their partners (Figure 1).

Fear of stigma and discrimination associated with positive test HIV/AIDS result was reported by 24 (8\%) of students. Students who reported unavailability of the service nearby and considering the service is not useful were

Table 1 Socio demographic characteristics of Debre Markos University students, March 2011

\begin{tabular}{|c|c|c|}
\hline Socio-demographic characteristics & Frequency & Percentage (\%) \\
\hline \multicolumn{3}{|l|}{ Residence } \\
\hline Urban & 305 & 42.9 \\
\hline Rural & 406 & 57.1 \\
\hline \multicolumn{3}{|l|}{ Sex } \\
\hline Male & 521 & 73.3 \\
\hline Female & 190 & 26.7 \\
\hline \multicolumn{3}{|l|}{ Marital status } \\
\hline Single & 651 & 91.6 \\
\hline Married & 52 & 7.3 \\
\hline Divorced/separated & 8 & 1.1 \\
\hline \multicolumn{3}{|l|}{ Age category } \\
\hline $15-24$ & 667 & 93.8 \\
\hline $25-34$ & 27 & 3.8 \\
\hline $35-44$ & 17 & 2.4 \\
\hline \multicolumn{3}{|l|}{ Educational status } \\
\hline First year & 279 & 39.3 \\
\hline Second year & 237 & 33.3 \\
\hline Third year & 195 & 27.4 \\
\hline \multicolumn{3}{|l|}{ Religion } \\
\hline Orthodox & 636 & 89.5 \\
\hline Muslim & 37 & 5.20 \\
\hline Protestant & 35 & 4.90 \\
\hline Others & 3 & 0.40 \\
\hline
\end{tabular}


Table 2 Knowledge, source of information about VCT service utilization and other characteristic of students within the last 12 months, Debre Markos University, March 2011

\begin{tabular}{|c|c|c|}
\hline Variables & Frequency & Percentage (\%) \\
\hline \multicolumn{3}{|c|}{ Perceived confidentiality of VCT } \\
\hline Yes & 579 & 81.4 \\
\hline No & 132 & 18.6 \\
\hline \multicolumn{3}{|c|}{ Source of information } \\
\hline Mass-media & 668 & 73.3 \\
\hline Health workers & 510 & 71.7 \\
\hline \multicolumn{3}{|c|}{$\begin{array}{l}\text { Knowledge about availability of ART in } \\
\text { the VCT site }\end{array}$} \\
\hline Yes & 607 & 85.4 \\
\hline No & 104 & 14.6 \\
\hline \multicolumn{3}{|c|}{ Perceived stigma after Positive result } \\
\hline Yes & 251 & 35.3 \\
\hline No & 460 & 64.7 \\
\hline \multicolumn{3}{|l|}{ Ever had Sex } \\
\hline Yes & 209 & 29.4 \\
\hline No & 502 & 70.6 \\
\hline \multicolumn{3}{|c|}{$\begin{array}{l}\text { Preferable ways of getting HIV test } \\
\text { result }\end{array}$} \\
\hline Face to face & 561 & 78.9 \\
\hline Secret letter & 118 & 16.6 \\
\hline others & 32 & 4.5 \\
\hline \multicolumn{3}{|l|}{ VCT utilization } \\
\hline Yes & 416 & 58.5 \\
\hline No & 295 & 41.5 \\
\hline \multicolumn{3}{|l|}{ HIV Risk perception } \\
\hline Yes & 473 & 66.5 \\
\hline No & 238 & 33.5 \\
\hline \multicolumn{3}{|l|}{ Age at first sex } \\
\hline $10-14$ & 3 & 1.4 \\
\hline $15-19$ & 104 & 50 \\
\hline $20-24$ & 89 & 42.8 \\
\hline $25-30$ & 12 & 5.8 \\
\hline \multicolumn{3}{|c|}{ Knowledge about HIV/AIDS } \\
\hline Knowledgeable & 682 & 96 \\
\hline Not knowledgeable & 29 & 4 \\
\hline \multicolumn{3}{|l|}{ Willingness to VCT } \\
\hline Yes & 626 & 88 \\
\hline No & 85 & 12 \\
\hline \multicolumn{3}{|c|}{ Perceived Importance of VCT } \\
\hline Yes & 691 & 97.2 \\
\hline No & 20 & 2.8 \\
\hline
\end{tabular}

account for 22 (9.1) and 20 (8.3) respectively (Table 3, Figure 1).

\section{Discussion}

Voluntary Counseling and Testing (VCT) is proven to be one of the most powerful weapons in halting the spread of HIV/AIDS. It is known to be a very important component of HIV/AIDS prevention strategies. Despite the fact that various studies have shown low utilization of VCT service particularly in developing countries this study tried to look in to the level and associated factors of VCT utilization by students in Debre Markos University (14).

The finding indicates that Knowledge of modes of HIV/ AIDS transmission and prevention among the students was high. $96 \%$ of the respondents were knowledgeable of HIV/AIDS transmission and prevention.

The result also revealed on sexual practice and perceived risk of becoming infected with HIV among the students. Of all the respondents $29.4 \%$ had sexual experience, of which, $50 \%$ started sex at the age of $15-$ 19 years. The respondents that felt being at risk of HIV infection comprised $66.5 \%$ of all.

In this study $81.4 \%$ of respondents heard about the availability of confidential VCT services and their major primary sources identified were mass-media and health workers.

The overall prevalence of VCT utilization in the past12 months was 416 (58.5\%) with slightly higher utilization by females as compared to males. This result is higher when compared with the health care professional students of Kilimanjaro region revealed that voluntary counseling and testing utilization was $34.5 \%[12,13]$. It is also higher than the study conducted among students in Bahir Dar University and Debre Birhan Teachers Teaching College with VCT utilization of 38.6 and 35.19 respectively $(15,17)$.

The possible reasons for this could be due to recent accelerated expansion of the VCT service carried out through an increased advocacy and social mobilization in higher institution as well as country-wide and the study participant explained by the high risk perception and more knowledge regarding the VCT benefits.

The most commonly cited reason that VCT users gave for getting an HIV test was $82 \%$ to know their status followed by $7 \%$ for marriage. This is similar with finding in Debre Birhan Teachers Teaching College which showed $84.15 \%$ and $12.20 \%$ respectively [15]. The two main reasons mentioned by study participant for not using VCT service were not feeling at risk and trusting one-self and their sexual partner.

Overall, $88 \%$ study subjects showed their willingness to undertake HIV counseling and testing in the future. However, this high percentage of willingness to take the VCT service by the study participants different from the 


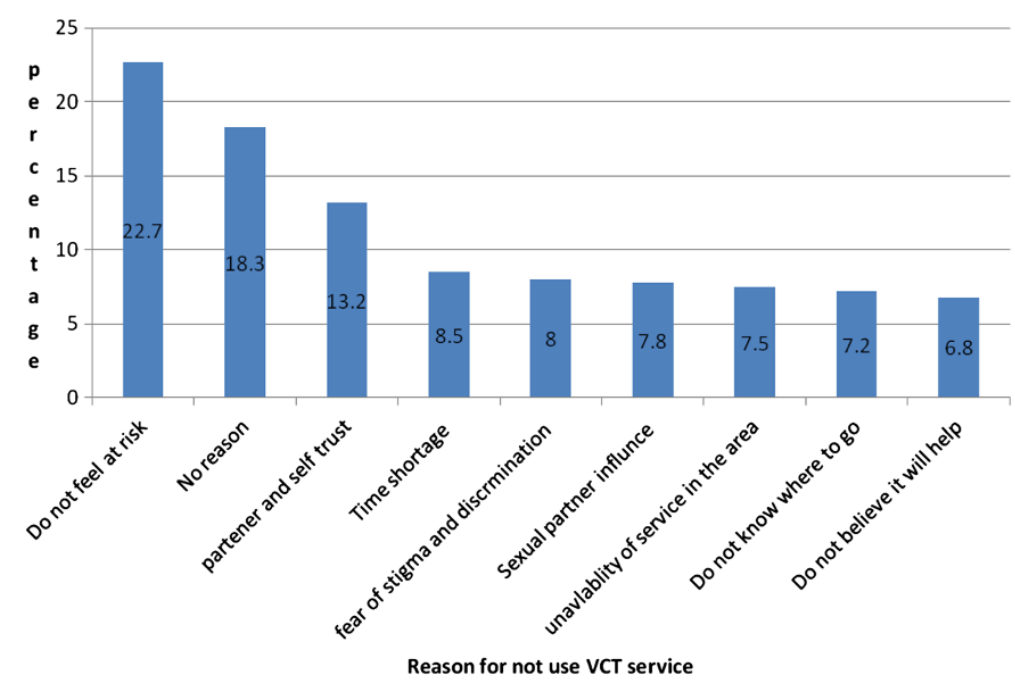

Figure 1 Bar chart showing reason given by the students for not using voluntary Counseling and testing service within the last 12 months, Debre Markos University, March 2011.

actual practice. This might be due to less mobilization activity and fear of testing and its consequences, other reasons to this may be due to lack of perceived benefits of VCT.

Knowledge about HIV/AIDS and VCT utilization has positive association. Students who have knowledge about HIV were 3.69 times more likely to utilize VCT service as compared to those who did not have knowledge about HIV. This finding is supported by the assumption that
VCT users could have more exposure/information/knowledge regarding HIV/AIDS before they came to VCT centers (15). This again may indicate the information to be disseminated through health education and counseling sessions may benefit from the inclusion of such topics during the respective sessions, and continuous mass media activity.

In this study, socio-demographic characteristics of the students were not significantly associated with VCT

Table 3 Associations of various characteristics of students by VCT service utilization within the last 12 months, Debre Markos University, March 2011

\begin{tabular}{|c|c|c|c|c|c|}
\hline \multirow[t]{2}{*}{ Variables } & \multicolumn{2}{|l|}{ VCT utilization } & \multirow[t]{2}{*}{ COR $(95 \% \mathrm{Cl})$} & \multirow[t]{2}{*}{ AOR $(95 \% \mathrm{Cl})$} & \multirow[t]{2}{*}{ P-value } \\
\hline & Yes $(n=416)$ & No $(n=295)$ & & & \\
\hline \multicolumn{6}{|l|}{ Knowledge of HIV } \\
\hline Knowledgeable & 407 & 275 & $3.3(1.47,7.33)$ & $3.69(1.19,11.49)$ & 0.04 \\
\hline Not knowledgeable & 9 & 20 & 1 & 1 & \\
\hline \multicolumn{6}{|l|}{ Confidentiality } \\
\hline Yes & 357 & 222 & $1.99(1.36,2.92)$ & $3.00(1.65,5.49)$ & 0.001 \\
\hline Non & 59 & 73 & 1 & 1 & \\
\hline \multicolumn{6}{|l|}{ Perceived risk } \\
\hline Yes & 351 & 111 & $8.95(6.28,12.70)$ & $2.40(1.37,4.23)$ & 0.002 \\
\hline No & 65 & 184 & 1 & 1 & \\
\hline \multicolumn{6}{|l|}{ Availability of ART } \\
\hline Yes & 375 & 232 & $2.48(1.62,3.80)$ & $3.11(1.62,5.99)$ & 0.001 \\
\hline No & 41 & 63 & 1 & 1 & \\
\hline \multicolumn{6}{|l|}{ Perceived stigma } \\
\hline Yes & 16 & 235 & $0.01(0.006,0.018)$ & $0.013(0.007,0.024)$ & 0.01 \\
\hline No & 400 & 60 & 1 & 1 & \\
\hline
\end{tabular}


service utilization, which is contradicted with the study conducted among students in Mekele University [16]. Possible reason could be recent accelerated expansion of the VCT service carried out through an increased advocacy targeting disparities in sex, region, religion, age and ethnicity etc.

This study identified the availability of ART as a positive predictor of VCT acceptance. Students who know the availability of ART in the VCT site were 3.12 times more likely to utilize VCT service as compared to those who didn't know availability of ART in the VCT site. The provision of ART would have a significant effect in prolonging life and this would have an impact on the students in creating positive attitude and acceptance towards the service. Making every effort to make ART available would increase VCT acceptance by all students and students, who perceive risks associated with the HIV/AIDS test result were 2.4 times more likely to utilize VCT service as compared to their counterpart.

In this study perceived stigma associated with the positive test result was found to be important factor of VCT service utilization. Students who perceive stigma and discrimination were 0.013 times less to likely utilize VCT service as compared to their counterparts. This is in line with the study in Bahir Dar University students, where perceived stigma and discrimination was known to be strong predictor of voluntary counseling and testing [17].

The other finding of this study was the positive association of presence of confidentiality on the VCT site and utilization of VCT service among students. Students who heard the presence of confidentiality in the VCT service site were 3 times more likely to utilize VCT service as compared with those who didn't hear the presence of confidentiality in the VCT service sites.

This study encountered a number of limitations, among which, as with any observational study, the possibility of residual confounding effect of some factors cannot be excluded. This may result in spurious associations of the factors with some events, and we thus guarded against this possibility by careful sequential building of models in our analyses. Another limitation of this study was findings from this study may not be generalized to the whole population of the young people because the study involved only those young people who are in higher institutions.

\section{Conclusion}

Firstly, majority of the students knew the existence of confidential VCT services and large proportion of them utilized the service. Secondly, five important variables were identified as predictors for the increased VCT service utilization. The odds of having used VCT significantly increased with knowing availability of ART drug in VCT site, heard presence of confidentiality, absence of perceived stigma, higher risk perception, and knowledge about HIV. Therefore, actions targeting on those predictors are necessary to effectively enhance the use of the VCT services which allows students to know their HIV sero-status and prepare for treatment or care which could represent a reasonable commitment towards HIV/ AIDS prevention in higher institutions.

\section{Competing interests}

The authors declare that they have no competing interests.

\section{Authors' contributions}

GT: conception and initiation of the study, design, implementation, analysis and writing. ME: design, implementation of the study and Co-writing. SM: design, implementation and co-writing. All authors read and approved the final manuscript.

\section{Authors' information}

Girmay (BSC, MPH) is lecturer at Debre Markos University, College of Medicine and Health Science, Debre Markos, Ethiopia.

Melkie (professor) is lecturer at Gondar University, college of Medicine and Health Science, Institution of Public Health, Gondar, Ethiopia.

Solomon (assistance professor) is lecturer at Gondar University, College of

Medicine and Health science, Institution of Public Health, Gondar, Ethiopia.

\section{Acknowledgements}

I am grateful to the Debre Markos University Administrative for granting us to communicate to different departments.

My special thanks and sincere appreciation also go to supervisors, data collectors, study participants and VCT counselors for contribution to the success of the data collection.

\section{Author details}

${ }^{1}$ School of public Health, College of Medicine and Health Sciences, Debre Markos University, Debre Markos, Ethiopia. ${ }^{2}$ School of Public Health, College of Medicine and Health Sciences, University of Gondar, Gondar, Ethiopia.

Received: 11 August 2012 Accepted: 3 January 2013

Published: 19 March 2013

\section{References}

1. UNAIDS: The global HIV/AIDS epidemic update, HIV/AIDS policy fact sheet. Geneva: UNAIDS; 2008.

2. UNAIDS/WHO: Global summary of the AIDS epidemic update. Geneva, Switzerland: World Health Organization; 2007.

3. FMOH/HAPCO: Single point HIV/AIDS prevalence estimate. Addis Ababa, Ethiopia; 2007

4. HAPCO/GAMET: HIVIAIDS in Ethiopia: an epidemiological synthesis, the global HIV/AIDS program. Addis Ababa, Ethiopia; 2008.

5. USAID: Going to Scale in Ethiopia: Mobilizing Youth Participation in a National HIV/AIDS Program. United State: USAID Health Care Improvement; 2010.

6. WHO: Scaling up priority HIV/AIDS interventions in the health sector, progress. United State: World Health Organization; 2010.

7. Bakilana A, Bundy D, Brown J, et al: Accelerating the Education Sector Response to HIV/AIDS in Africa: A review of World Bank assistance, World Bank global HIV/AIDS program discussion paper. Washington, DC: World Bank; 2005:1-5.

8. Bennell P, Hyde K, Swainson N: Impact of the HIV/AIDS Epidemic on the Education Sector in Sub-Saharan Africa: A synthesis of the findings and recommendations of three Country studies, centre for international education. Ethiop J Health Dev 2009, 23(3).

9. The U.S. President's Emergency Plan for AIDS Relief (PEPFAR): HIV Counseling and Testing. United States of America Combat HIV/AIDS; 2009.

10. FMoH/HAPCO: Guidelines for HIV/AIDS Counseling and Testing in Ethiopia. Addis Ababa: FMoH; 2007.

11. FMoH/HAPCO: HIV/AIDS Behavioral Surveillance Survey (BSS II). Addis Ababa, Ethiopia: FMoH; 2005:148-154.

12. Charles MP, Kweka EJ, Mahande AM, Barongo LR, et al: Evaluation of uptake and attitude to voluntary counseling and testing among health 
care professional students in Kilimanjaro region, Tanzania. BMC Public Health, 9:128.

13. Pauline E: Jolly, acceptance of voluntary counseling, \& testing and treatment for HIV among pregnant women in Kumasi, Ghana. Med J 2008, 42(1):8-15.

14. Population Council, Horizons Program: HIV Voluntary Counseling and Testing Among Youth: Results from an Exploratory Study in Nairobi, Kenya, Kampala and Masaka, Uganda. Washington, DC: USAID; 2008.

15. Zeytu G: Knowledge, attitude towards practicing of voluntary HIV counseling and testing and the determinants of VCT uptake: a case study in Debre Birhan students training college. South Africa: Statistics South Africa; 2007.

16. Alemayehu B: Attitude and Practice of Voluntary Counseling and Testing for HIV among University Students. Northern Ethiopia: Tigray, Mekele University; 2008.

17. Nebiyu H: Assessment of factors affecting HIV voluntary counseling and testing uptake among Bahir dar university students, Bahir dar town. Addis Ababa: University electronic library; 2008.

doi:10.1186/1471-2458-13-243

Cite this article as: Tsegay et al.: Assessment of voluntary counseling and testing service utilization and associated factors among Debre Markos University Students, North West Ethiopia: a cross-sectional survey in 2011. BMC Public Health 2013 13:243.

\section{Submit your next manuscript to BioMed Central and take full advantage of:}

- Convenient online submission

- Thorough peer review

- No space constraints or color figure charges

- Immediate publication on acceptance

- Inclusion in PubMed, CAS, Scopus and Google Scholar

- Research which is freely available for redistribution 